\title{
O impacto das publicações de acesso aberto na difusão da produção científica
}

Em 2009, a Paideia chega à plena maturidade, com novo visual e formatação arrojada, que a colocaram no patamar das maiores publicações em Psicologia do contexto nacional. Com a consolidação de seu novo projeto gráfico, a Paideia inaugurou um novo período em sua história, com desenho de capa e diagramação totalmente remodelados, adequando-se, assim, ao formato mais aceito internacionalmente.

As realizações e os êxitos alcançados revelam o vigor e a disposição de uma revista dinâmica, que conquistou posição de destaque no cenário nacional e que começa sua caminhada rumo ao reconhecimento internacional, todavia, com plena consciência de que ainda tem um longo caminho a seguir para sua consagração. Bem avaliada no Qualis Periódicos da CAPES, com conceito B1, a revista tem buscado ampliar a publicação de artigos científicos de elevada qualidade, que contribuam com o avanço das pesquisas.

Como é do conhecimento geral, a Paideia é uma publicação quadrimestral disponível integralmente na Biblioteca Científica Eletrônica Online - SciELO Brasil. Disponibilizamos no site www.scielo.br/paideia os fascículos referentes ao volume 8 número 14/15 de 1998 em diante, dando prosseguimento à política de dar visibilidade e acesso aberto ao acervo completo da revista, iniciada em 2008. Assim, contamos até a presente data com 30 fascículos disponibilizados. Esta é a contribuição singular da Paideia para uma ampla democratização do acesso à produção científica e acadêmica.

É imperativo reconhecer o papel fundamental da política de acesso aberto para o enriquecimento de nossa comunidade acadêmica. Disponibilizar os artigos online permite à Paideia agilizar e ampliar o acesso ao conhecimento científico produzido no campo da Psicologia, Educação e áreas afins, que constitui o escopo da revista.

Estudos recentes comprovam o impacto das publicações de acesso aberto no aumento das citações a artigos científicos. Embora sua influência seja mais modesta do que havia sido estimado anteriormente - está em torno de $8 \%$ para pesquisas publicadas recentemente, segundo um estudo publicado em 20 de fevereiro de 2009 na revista Science -, publicar artigos em periódicos vinculados a serviços de acesso livre e gratuito aumenta a quantidade de citações que os autores recebem. Mesmo não sendo tão elevado como se estimava, ainda assim o impacto é significativo, especialmente nos países em desenvolvimento. De fato, os resultados do estudo indicaram que a influência da publicação em acesso aberto foi mais do que duas vezes maior nos países em desenvolvimento em comparação com os mais ricos. Esses achados fortalecem a política de livre acesso à produção acadêmica e científica.

Diversidade de temas e pluralidade metodológica enfeixam este fascículo 19, número 43 da Paideia. Questões emergentes na contemporaneidade, como o sistema de cotas na universidade pública, o sentido da morte para grupos religiosos, interações da família com o abrigo, são tematizadas nos estudos publicados. Outros temas contemplados foram: intervenção junto à instituição de educação infantil, o brincar, apego materno, personalidade de mulheres adolescentes infratoras, o trabalho em equipe, o papel do psicólogo hospitalar, bem como atuação na atenção primária à saúde. Complementam o grande arco da diversidade das temáticas abordadas os artigos dedicados à utilização de uma ferramenta em estudos que envolvem apreciação musical, bem como à avaliação do viés de atenção em mulheres com Transtorno de Ansiedade Generalizada.

A origem dos pesquisadores também é bastante diversificada, abarcando desde autores oriundos de países da América do Sul e do Norte a autores nacionais, de diferentes regiões geográficas e de um amplo espectro de instituições, o que é indicativo da ampla disseminação da revista e sua penetração capilar pela rede nacional e internacional.

A seção destinada aos artigos é aberta com o estudo internacional Caracterización de personalidad de mujeres adolescentes infractoras de ley: un estudio comparativo, de Eugenia Vinet e Paula Alarcón Bañares, da Universidad de La Frontera, Chile, que investiga as características de personalidade de um grupo de adolescentes infratoras comparadas a jovens infratores do sexo masculino e do sexo feminino com problemas de saúde mental. As autoras concluem que o perfil em questão é semelhante ao descrito pela literatura internacional e deve ser levado em consideração no planejamento e efetivação de serviços de assistência a jovens delinquentes.

A segunda contribuição, de autoria compartilhada BrasilFrança, intitulada Escala multidimensional aplicada aos estudos de apreciação musical, de Raquel Cocenas da Silva e José Lino Oliveira Bueno, da Universidade de São Paulo, Ribeirão Preto, Emmanuel Bigand e Paul Molin, da Université de Bourgogne, França, versa sobre as propriedades da escala multidimensional, importante instrumento para análise exploratória de dados e investigação da representação mental de estímulos, que vem sendo utilizada não apenas por psicólogos, mas também por pesquisadores de outras áreas. Trata-se de estudo inédito, que utiliza tal instrumento na pesquisa sobre de estímulos musicais e percepção subjetiva de tempo.

Na sequência, o artigo Construção e validação de tarefa de Stroop Emocional para avaliação de viés de atenção em mulheres com Transtorno de Ansiedade Generalizada, de Débora Cristina Fava e Christian Haag Kristensen, da Pontifícia Universidade Católica do Rio Grande do Sul, Wilson Vieira Melo e Lisiane Bizarro Araujo, da 
Universidade Federal do Rio Grande do Sul, investiga a existência de viés para palavras ameaçadoras em mulheres com Transtorno de Ansiedade Generalizada, a partir da tarefa de Stroop Emocional, instrumento amplamente conhecido na Psicologia.

$\mathrm{O}$ artigo Psicologia na atenção primária à saúde: reflexões e implicações práticas, de Juliane Fernandes Simões de Mattos Andrade, da Universidade Federal de São Carlos, e Cristiane Paulin Simon, da Universidade Federal do Triângulo Mineiro, discute as práticas de psicólogos em contextos de atenção primária à saúde, por meio de entrevistas realizadas com esses profissionais. As autoras revelam que há predomínio de ações no âmbito clínico, a despeito dos pressupostos da assistência integral à saúde, evidenciando a importância de implementar modificações na estrutura curricular de cursos de Psicologia, no sentido de dar maior relevo aos estudos e ações desenvolvidos no âmbito da saúde pública.

Dando continuidade às pesquisas relativas à Psicologia da Sáude, Trabalho de equipe em reabilitação: um estudo sobre a percepção individual e grupal dos profissionais de saúde, de autoria de Elizabeth Queiroz e Tereza Cristina Cavalcanti Ferreira de Araujo, da Universidade de Brasília, identificaram e compararam a percepção individual e grupal dos profissionais de dois serviços de reabilitação de um mesmo hospital acerca do trabalho em equipe. Os dados coligidos por meio de entrevistas individuais e grupais complementaram-se, permitindo destacar a relevância de combinar essas técnicas na realização de estudos desse tipo.

A contribuição seguinte, de natureza teórica, também contempla o profícuo diálogo entre Psicologia e Saúde. $O$ psicólogo no hospital geral: estilos e coletivos de pensamento, de Fabia Monica Souza dos Santos da Universidade Estácio de Sá, e Ana Maria Jacó-Vilela da Universidade do Estado do Rio de Janeiro, reflete sobre os fundamentos da prática do psicólogo na área da Saúde, sobretudo no âmbito hospitalar, a partir do conceito de estilo de pensamento e coletivo de pensamento desenvolvidos por Fleck. As autoras ponderam a importância de resgatar a história das instituições e da constituição das subjetividades, diante da multiplicidade de paradigmas que comportam a Psicologia e demais Ciências Humanas que a influenciam.

$\mathrm{Na}$ sequência, $O$ sentido da morte para protestantes e neopetencostais, de Ana Keila Mosca Pinezi da Universidade Federal do ABC, discorre sobre o sentido da morte para dois grupos evangélicos distintos, a partir de trabalho de campo etnográfico com fiéis dessas instituições. O estudo é fundamentado na Antropologia hermenêutica proposta por Geertz. A autora destaca que as noções e ritos relacionados à morte para ambos os grupos variam, o que denota a necessidade de sermos sensíveis para as diferenças em relação à vivência da finitude humana.

$\mathrm{O}$ artigo Vinculação da gestante e apego materno fetal, de autoria de Eluisa Bordin Schmidt da Universidade Regional Integrada do Alto Uruguai e das Missões, e Irani Iracema de Lima Argimon da Pontifícia Universidade Católica do
Rio Grande do Sul, verificara as relações entre o tipo de vinculação da gestante e apego com seu bebê ainda intra-útero e a presença ou não de sintomas de ansiedade e depressão. As gestantes preencheram uma série de escalas específicas para o objeto em questão, cujos resultados foram analisados quantitativamente e indicaram associação significativa entre o tipo de vinculação da gestante e apego materno fetal.

$\mathrm{O}$ trabalho Um estudo ecológico sobre as interações $d a$ família com o abrigo, assinado por Queila Almeida Vasconcelos da Universidade Federal do Amazonas, Maria Angela Mattar Yunes e Narjara Mendes Garcia da Universidade Federal do Rio Grande, perscrutou as interações entre famílias e instituições de abrigo a partir do modelo bioecológico de desenvolvimento humano de Bronfenbrenner. Os profissionais do abrigo revelaram concepções idealizadas de família e cuidados à criança, por sua vez, os familiares demonstraramse receosos diante dos julgamentos dos profissionais, sobretudo em virtude da possibilidade de perderem a guarda de outros filhos.

Ainda no âmbito da Psicologia do Desenvolvimento, o trabalho Promovendo saúde e desenvolvimento na educação infantil: uma atuação da Psicologia, de Samira Mafioletti Macarini, Gabriela Dal Forno Martins e Mauro Luis Vieira, da Universidade Federal de Santa Catarina, apresenta os resultados de um estágio realizado em uma instituição de educação infantil, no contexto de promoção da saúde. A partir da abordagem bioecológica, as estagiárias definiram demandas para atuação, que foram atendidas mediante diversas intervenções com os membros do sistema em questão. Os resultados permitem ressaltar a importância da parceria crechefamília para a promoção do desenvolvimento dos infantes.

Dando sequência às discussões sobre práticas educativas, o artigo teórico Uma análise comportamentalista de relatos verbais e práticas educativas parentais: alcance e limites, de autoria de Vanessa Barbosa Romera Leme, Alessandra Turini Bolsoni-Silva e Kester Carrara, da Universidade Estadual Paulista Júlio de Mesquita Filho, reflete sobre a aplicabilidade dos recursos da Análise Aplicada do Comportamento para examinar práticas educativas parentais, o que vem sendo referendado por diversos estudos da literatura.

Dando continuidade à temática anterior, o trabalho $A$ influência socieconômica e cultural no brincar de pré-escolares, de Luzia Iara Pfeifer, Patrícia Gonçalves Rombe e Jair Licio Ferreira Santos, da Universidade de São Paulo, Ribeirão Preto, investiga diferenças entre os brinquedos utilizados por crianças de classes socioeconômicas distintas, a partir de um questionário respondido por suas mães.

Encerrando a seção de artigos, o estudo Afetividade entre estudantes e sistema de cotas para negros, de Maria da Penha Nery e Liana Fortunato Costa, da Universidade de Brasília, aborda as relações afetivas entre estudantes cotistas e não-cotistas desta instituição de ensino superior. A partir da abordagem sociodramática, as autoras investigam as implicações afetivas e identitárias desse tipo de política, 
tema candente no cenário brasileiro, que merece ser refletido com apoio do arcabouço teórico das diversas disciplinas das Ciências Humanas, a fim de compreendê-lo em sua complexidade.

Na seção seguinte, destinada à comunicação breve, o trabalho Clínica e linguagem ou o furo na prática, assinado por Marcus André Vieira da Pontifícia Universidade Católica do Rio de Janeiro, apresenta reflexões oportunas para a clínica psicanalítica, particularmente para aqueles que partilham da abordagem lacaniana.

Por fim, a última seção dedica-se à resenha Leitura, escrita e compreensão, de Geraldina Porto Witter da Universidade Camilo Castelo Branco. A autora apresenta o livro Reading and writing with understanding, de Sally Hampton e Lauren B. Resnick, publicado pela editora IRA.

Este número se encerra com as Normas de Publicação. Esperamos que os leitores possam ter uma leitura profícua e que se sintam mobilizados a submeterem suas próprias contribuições à avaliação da revista. $\mathrm{O}$ período para submissões é aberto o ano todo e os interessados em contribuir para o enriquecimento do debate crítico sobre a pesquisa devem consultar as normas de publicação no site da SciELO. No momento, um processo de mudança para o sistema Submission da SciELO está em curso. Temos pela frente o desafio de, em breve, implantar a submissão online.

Que os frutos da dedicação e do empenho colhidos até o momento nos impulsionem a prosseguir em direção a novas conquistas. No horizonte dos novos desafios reconhecemos a necessidade de ampliar a indexação no país e no exterior, implantar a submissão online e apresentar excelentes indicadores bibliométricos.

Que tenhamos energia e inspiração para empreendermos o combate necessário.

Manoel Antônio dos Santos

Editor 